\title{
Corrigendum: Hunger in Vulnerable Families in Southeastern Europe: Associations With Mental Health and Violence
}

\author{
Elena Jansen ${ }^{1 *}$, Jamie M. Lachman ${ }^{2,3}$, Nina Heinrichs ${ }^{4}$, Judy Hutchings ${ }^{5}$, Adriana Baban ${ }^{6}$ \\ and Heather M. Foran ${ }^{1}$ \\ ${ }^{1}$ Institute of Psychology, Alps-Adria University, Klagenfurt am Woerthersee, Austria, ${ }^{2}$ Department of Social Policy and \\ Intervention, University of Oxford, Oxford, United Kingdom, ${ }^{3} \mathrm{MRC} / \mathrm{CSO}$ Social and Public Health Sciences Unit, University of \\ Glasgow, Glasgow, United Kingdom, ${ }^{4}$ Department of Psychology, University of Bremen, Bremen, Germany, ${ }^{5}$ School of \\ Psychology, Bangor University, Wales, United Kingdom, ${ }^{6}$ Department of Psychology, Babeş-Bolyai University, Cluj-Napoca, \\ Romania
}

Keywords: hunger, food insecurity, violence, mental health, support, socioeconomic status

\section{OPEN ACCESS}

Approved by:

Frontiers Editorial Office,

Frontiers Media SA, Switzerland

${ }^{*}$ Correspondence:

Elena Jansen

elena.jansen@aau.at

Specialty section:

This article was submitted to

Inequalities in Health,

a section of the journal

Frontiers in Public Health

Received: 31 May 2020

Accepted: 16 June 2020

Published: 29 July 2020

Citation:

Jansen E, Lachman JM, Heinrichs N, Hutchings J, Baban A and Foran HM (2020) Corrigendum: Hunger in Vulnerable Families in Southeastern Europe: Associations With Mental Health and Violence.

Front. Public Health 8:336. doi: 10.3389/fpubh.2020.00336

\section{A Corrigendum on}

Hunger in Vulnerable Families in Southeastern Europe: Associations With Mental Health and Violence

by Jansen, E., Lachman, J. M., Heinrichs, N., Hutchings, J., Baban, A., and Foran, H. M. (2020). Front. Public Health 8:115. doi: 10.3389/fpubh.2020.00115

In the original article, we neglected to include the funder Faculty of Humanities at the AlpsAdria University Klagenfurt, to Elena Jansen covering the article processing charges. The corrected Funding statement appears below.

The authors apologize for this error and state that this does not change the scientific conclusions of the article in any way. The original article has been updated.

\section{FUNDING}

This project has received funding from the European Union's Horizon 2020 research and innovation program under grant agreement No. 779318. Funding includes financial, material, and personnel support. Time period for funding: 1 January 2018 to 31 December 2021. Contact details: European Commission, DG Research and Innovation, 1049 Bruxelles, Belgium. The funder was not and will not be involved in the design of the study, the collection, analysis and interpretation of data, or the writing of the protocol. Funding was also provided to EJ from the Faculty of Humanities at the Alps-Adria University Klagenfurt to cover the article processing charges.

Copyright (C) 2020 Jansen, Lachman, Heinrichs, Hutchings, Baban and Foran. This is an open-access article distributed under the terms of the Creative Commons Attribution License (CC BY). The use, distribution or reproduction in other forums is permitted, provided the original author(s) and the copyright owner(s) are credited and that the original publication in this journal is cited, in accordance with accepted academic practice. No use, distribution or reproduction is permitted which does not comply with these terms. 